\title{
CAROTENOIDS IN MAN. THE DISTRIBUTION OF EPIPHASIC CAROTENOIDS IN ATHEROSCLEROTIC LESIONS ${ }^{1}$
}

\author{
BY DAVID H. BLANKENHORN, DAVID G. FREIMAN,2 AND \\ HARVEY C. KNOWLES, JR.

\begin{abstract}
(From the Metabolism Laboratory of the Department of Medicine, and the Department of Pathology, University of Cincinnati College of Medicine, Cincinnati, O.)
\end{abstract}

(Submitted for publication May 25, 1956; accepted July 25, 1956)

Carotenoid pigments are yellow and red colored lipids widely distributed throughout nature. Those most commonly encountered contain 40 carbon atoms and have structures closely related to that of lycopene (Figure 1). Approximately 80 carotenoid pigments are known, each with a characteristic absorption spectrum. In some, closed rings are present at the ends of the molecule, while others contain one or more moles of oxygen in carbonyl or hydroxyl groups. Carotenoids containing no hydroxyl groups are called epiphasic carotenoids because when equilibrated between two immiscible solvents (petroleum ether and aqueous 90 per cent methanol), they pass completely into the petroleum ether epiphase.

Certain carotenoids (chiefly epiphasic) can be converted to Vitamin A, and their role in human nutrition has been extensively studied (1). Carotenoids have long been known to contribute to the yellow color of human depot fat, adrenal cortex, and atheromatous plaques (2), but this phenomenon has attracted little attention. Since studies of carotenoids as provitamins A have demonstrated that they cannot be synthesized by man, their occurrence in atheromatous plaques provides evidence that a dietary lipid may be deposited in the lesions of this disease. Accordingly, the concentrations of total epiphasic carotenoids and total cholesterol were studied in thirty human aortas having varying degrees of atherosclerosis. The findings indicate that atherosclerotic lesions of the aorta accumulate carotenoids in amounts related to the age and extent of the lesions.

\footnotetext{
1 Supported by Grants in Aid from The American Heart Association and the Youngstown Area Heart Association, and in part by the John R. Stack Research Fund.

2 Present address : Beth Israel Hospital, Boston, Mass.
}

\section{METHODS}

1. Collection of specimens. The aortae were obtained without selection from autopsies performed on patients ranging in age from 10 to 90 years. After removal from the body the aortae were stored at 4 degrees centigrade under a moist towel for periods up to 48 hours before examination and dissection. An arbitrarily chosen standard segment 3 inches long, which included the entire width of the descending arch just caudal to the left subclavian artery, was studied in all cases. In 12 patients, 2 additional segments were studied. These latter specimens also included the entire width of the aorta and were 3 inches long. They were measured cephalad from the coeliac axis and the bifurcation of the aorta respectively. Segments were cut to measure and then stripped of adventitia in preparation for grading.

2. Grading of atherosis. The segments were graded for extent and character of atherosclerosis in the following manner :

Extent: The extent to which the atherosis involved the intima was graded 1 to 4 , depending on whether 1 to 25 per cent, 25 to 50 per cent, 50 to 75 per cent or 75 to 100 per cent of the intimal surface of the segment appeared to be covered by plaques.

Character: The character of the most representative plaque was assigned a grade of 1 to 4 according to a descriptive scheme based on the assumption that the morphology of atherosclerotic plaques changes in a serial manner. The characteristics graded are in all probability related to the age of the lesions. However, the rate at which atherosclerotic lesions undergo change is uncertain. Moreover, it is unknown whether all lesions change at the same rate. Consequently, only relative age can be judged.

The criteria used for assigning a grade are outlined below :

Grade 1. Gross: Visible intimal thickening and gelatinous non-yellow translucent discrete plaques. Microscopic: Thickening and edema of the intima, without distinct plaque formation.

Grade 2. Gross: Yellow, opaque plaques without evidence of calcium present. Microscopic: Well-defined lipid laden plaques, the lipid being primarily contained within macrophages. Moderate amounts of extracellular cholesterol and minimal intimal fibrosis overlying the lipid- 


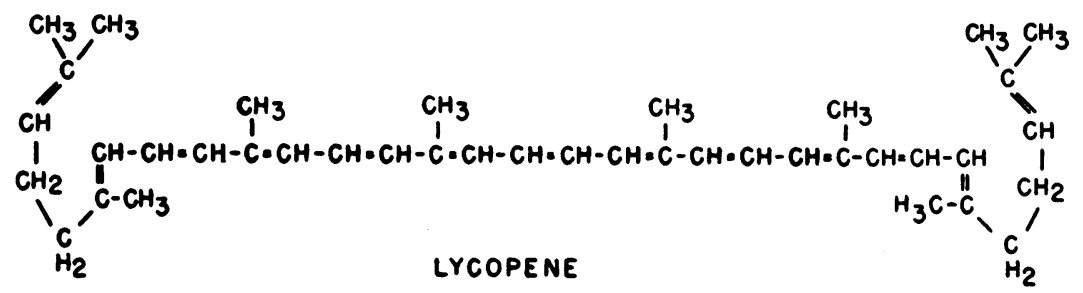

FIGURE 1

containing areas were considered compatible with this grade.

Grade 3. Gross: Thick pale gray-white lesions, often confluent, with evidence of fibrosis and calcification present. Microscopic: Plaques with lipid predominantly extracellular and with a significant intimal fibrosis over the lipid mass. Few lipid containing macrophages and minimal calcification and ulceration present.

Grade 4. Gross: Changes more severe than grade 3, including ulceration, calcification or medial involvement. Microscopic: Lesions showing more severe changes than seen in lower grades, including increased fibrosis, calcification, ulceration and almost completely extracellular lipid.

This scheme for grading atherosclerosis deserves special mention. It represents an attempt to classify the morphology of atherosclerosis so that the results of chemical assay may be placed in the perspective of pathologic anatomy. In this scheme two attributes of the lesion are estimated, their extent and their character or relative age. The severity of atherosclerosis is considered to be a function of these two attributes.

To test the validity of this plan of grading, the specimens were assayed for total cholesterol since cholesterol is the major lipid found in atherosclerotic plaques (3-6), and because previous workers have shown that the amount of atherosclerosis found in the aorta is proportional to its cholesterol content $(5,6)$. To minimize the effect of individual variation in size, thickness and water content of the aorta, the data have been expressed in milligrams of cholesterol per square centimeter of intimal surface as suggested by McMillan, Horlick, and Duff (7). In Figure 2 the individual cholesterol content per square centimeter of each of 30 segments of thoracic aorta is plotted against the grade assigned to that segment. The grades of extent and relative age are plotted separately, followed by a plot of the average of these two grades. A significant relation $(t=6.2)$ is demonstrated between the average grade and cholesterol content per square centimeter. Accordingly, it is believed that this grading scheme is a valid basis for the rough quantitation of the severity of atherosclerosis. Severity, as used hereafter, is defined as a term for semi-quantitative description of atherosclerosis which is estimated by averaging two numerical grades, one of which indicates the extent of the lesion, the other its relative age or character.

In its present state this grading scheme is considered to be only semi-quantitative. However, further refinement and application of this technique may yield information of value. In Figure 2 the first two plots shown demonstrate that there is no significant difference $(p>0.5)$ between the relation of the cholesterol content per square centimeter and the extent and relative age of the lesions. The segments of mid-abdominal and lower abdominal aorta studied also showed this finding. It would be of interest to know to what extent this relation applies to the remainder of the vascular tree in man.

When segments are graded grossly the judgment of the

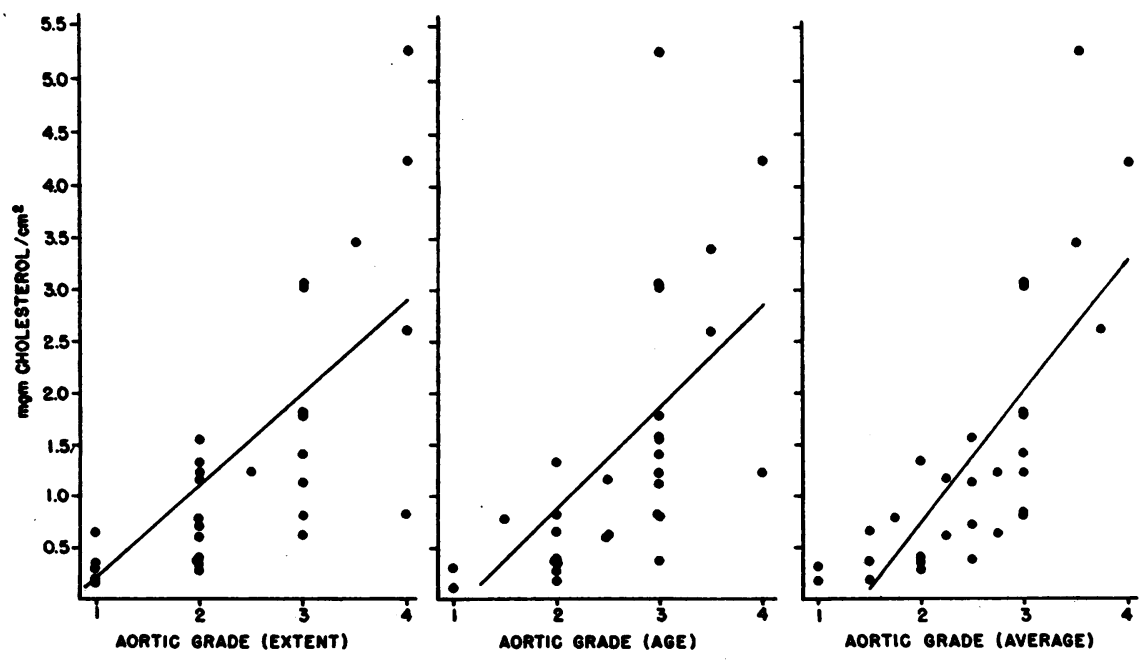

Fig. 2. The Cholesterol Content of the Human Aorta 
examiner as to the character of the most common plaque may be influenced by the degree to which the intimal surface is covered by atheroma. However, this error is excluded when grading is done microscopically. When 16 plaques from different aortas in this series were graded both grossly and microscopically, a satisfactory agreement between the estimates was found. Thirteen plaques were placed in the same group, two were graded a group too high grossly and one a group too low.

3. Preparation of tissue for assay. After gross grading, several radial cuts were made in the specimen to make it lie flat, then it was placed on Whatman No. 50 filter paper and traced. Later the area of each segment was determined to the nearest $0.1 \mathrm{~cm}$., with a polar planimeter. Pressed between two filter papers, the specimen was dried for 48 hours at approximately $0.5 \mathrm{~cm}$. mercury vacuum over $\mathrm{CaSO}_{4}$ at room temperature, and then weighed. It was next ground to a twenty mesh powder in an intermediate model Wiley Mill, and the powder brought to constant weight over $\mathrm{CaSO}_{4}$ for assay of carotenoid and cholesterol content.

4. Analytical methods. Total epiphasic carotenoids and total cholesterol were determined using a combination of several preexisting techniques for carotenoid and cholesterol analysis in serum (8-11). Approximately 250 -mg. aliquots of powdered aorta were washed with $3.0 \mathrm{cc}$. of water into red, glass-stoppered cylinders. After addition of $3.0 \mathrm{cc}$. of freshly made $1.0 \mathrm{~N} \mathrm{KOH}$ in 90 per cent ethanol, the cylinders were loosely stoppered, heated to their necks in a water bath at $50^{\circ}$ to $60^{\circ} \mathrm{C}$. for 30 minutes, and shaken vigorously at 10 -minute intervals. The cylinders were then allowed to cool to room temperature, $6.0 \mathrm{cc}$. of Hexane (Skelly-solve B) were added, and the stoppers tightly sealed with a small drop of mineral oil. The cylinders were rotated end over end mechanically for 10 minutes, and allowed to stand for 10 minutes. Four cc. of the upper phase were transferred to a $16 \times 100 \mathrm{~mm}$. optically matched test tube cuvette and tightly stoppered. Optical density was measured in a Beckman DU spectrophotometer with test tube attachment at 440 mu., employing a blue sensitive phototube and 0.14 slit. For cholesterol determination an aliquot of the Hexane phase was transferred to a second matched test tube cuvette and dried at water vacuum. Two cc. of glacial acetic acid were added to each tube and heated with stirring in boiling water for 15 seconds. The procedure from this point forward was that of Sperry and Webb (11). A cholesterol standard, prepared in the manner of Abell, Levy, Brodie, and Kendall (10) and carried through the entire procedure was used as a solvent blank for the carotenoid determination and to supply an internal standard for the cholesterol determination.

All solvents used were reagent grade, except ethanol which was USP, and all were redistilled. Test tubes (A. H. Thomas and Co. No. 9446) used as optical cuvettes were matched to a 0.3 per cent transmission using 0.7 millimolar aqueous potassium dichromate against an air blank. Carotenoid content was calculated using the molecular extinction $E_{400}^{\prime}=231 \times 10^{3}$ which was deter- mined experimentally for this instrument using a mixture of Alpha and Beta Carotene. The published values of $E_{4+0}^{\prime}$ for the major epiphasic carotenoids known to be present in human tissue are: Alpha Carotene $\mathrm{E}_{440}^{\prime}=$ $310 \times 10^{3}$, Beta Carotene $\mathrm{E}^{\prime}{ }_{40}=330 \times 10^{3}$, Lycopene $E_{4+0}^{\prime}=210 \times 10^{3}$ (12). Bile pigments do not interfere with the determination (13).

Fifty-two samples from 30 patients were analyzed. All analyses were carried out in duplicate or triplicate as indicated. Duplicate analyses of aorta revealed average deviations from the mean of \pm 3.3 per cent for cholesterol, \pm 5.0 per cent for carotenoids when the aortic carotenoid content was in excess of $.05 \mu \mathrm{g}$. per $\mathrm{cm}^{2}$ and \pm 12 per cent when the content was less than this amount. When the range of values exceeded 5 per cent of the mean, triplicate or quadruplicate determinations were made if sufficient material was available. Recoveries of added carotenoid to aortic powder ranged from 88 per cent to 93 per cent regardless of whether the initial content was low or high, respectively. The high range of analytical error found in samples with low carotenoid content resulted from production of insufficient color to stay in the effective range of the instrument (14). Nevertheless, the magnitude of change encountered in different samples was so great that error in duplication was insignificant in final evaluation of data.

\section{RESULTS AND DISCUSSION}

In Table I are given the carotenoid and cholesterol contents of the aortas studied. The findings are listed serially by severity of atherosclerosis, and by cholesterol content within each grade of severity, as the values did not appear to be influenced by the area from which the segments were taken, or by the age, sex, or state of nutrition of the patient.

The data given in Table I have been divided into serial quarters and the average severity, average carotenoid content, average cholesterol content, average carotenoid-cholesterol ratio of each quarter are shown in Table II. With increase in the severity of the lesions, there were accompanying significant increases in carotenoid and cholesterol contents. However, the small increase in carotenoid-cholesterol ratio was not significant $(\mathrm{p}>0.1)$.

The relative constancy of the carotenoid-cholesterol ratio is worthy of comment. Cholesterol is the major lipid present in atherosclerosis (3-6), but it is not known whether it accumulates from outside the plaques or is formed in situ. It is generally accepted that carotenoids are derived from exogenous sources. In man, dietary depletion of these pigments decreases their blood and 
TABLE I

Total epiphasic carotenoid and cholesterol content of the human aorta

\begin{tabular}{|c|c|c|c|c|c|c|}
\hline $\begin{array}{l}\text { Severity of } \\
\text { atherosclerosis* }\end{array}$ & $\begin{array}{c}\text { Cholesterol } \\
\mathrm{mg} . / \mathrm{cm} .^{2}\end{array}$ & $\begin{array}{l}\text { Carotenoids } \\
\mu \mathrm{g} . / \mathrm{cm} . .^{2}\end{array}$ & Ratiof & $\begin{array}{c}\text { Aortic } \\
\text { zonef }\end{array}$ & $\begin{array}{c}\text { Age and } \\
\text { sex } \S\end{array}$ & $\begin{array}{l}\text { Final state } \\
\text { of nutrition } \|\end{array}$ \\
\hline 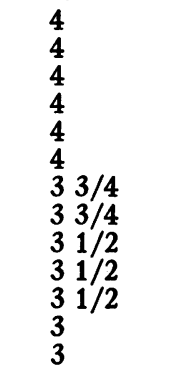 & $\begin{array}{l}8.76 \\
5.25 \\
4.40 \\
4.25 \\
2.79 \\
1.97 \\
4.05 \\
2.62 \\
5.29 \\
3.47 \\
1.14 \\
3.86 \\
3.07\end{array}$ & $\begin{array}{r}1.92 \\
.46 \\
.46 \\
.79 \\
.48 \\
.17 \\
.57 \\
.37 \\
1.18 \\
.60 \\
.11 \\
.23 \\
1.12\end{array}$ & $\begin{array}{l}.22 \\
.09 \\
.10 \\
.19 \\
.17 \\
.09 \\
.14 \\
.14 \\
.22 \\
.17 \\
.10 \\
.06 \\
.35\end{array}$ & $\begin{array}{l}\text { MA } \\
\text { LA } \\
\text { LA } \\
\text { Th } \\
\text { LA } \\
\text { LA } \\
\text { LA } \\
\text { Th } \\
\text { Th } \\
\text { Th } \\
\text { MA } \\
\text { MA } \\
\text { Th }\end{array}$ & $\begin{array}{l}67 \mathrm{M}(5) \\
78 \mathrm{M}(1) \\
67 \mathrm{M}(5) \\
77 \mathrm{M}(20) \\
67 \mathrm{M}(6) \\
61 \mathrm{~F}(24) \\
64 \mathrm{M}(2) \\
56 \mathrm{~F}(29) \\
60 \mathrm{~F}(30) \\
76 \mathrm{~F}(14) \\
61 \mathrm{~F}(24) \\
78 \mathrm{M}(1) \\
54 \mathrm{~F}(13)\end{array}$ & $\begin{array}{l}\text { WN } \\
\text { E } \\
\text { WN } \\
\text { WN } \\
\text { WN } \\
\text { E } \\
\text { PN } \\
\text { PN } \\
\text { WN } \\
\text { WN } \\
\text { E } \\
\text { E } \\
\text { WN }\end{array}$ \\
\hline $\begin{array}{l}3 \\
3 \\
3 \\
3 \\
3 \\
3 \\
3 \pi \\
3 \\
3 \\
3 \\
3 \\
2 \\
2 \\
2 \\
3 / 4\end{array}$ & $\begin{array}{r}3.04 \\
2.44 \\
1.83 \\
1.82 \\
1.79 \\
1.41 \\
1.23 \\
1.06 \\
.84 \\
.82 \\
.81 \\
1.24 \\
.63\end{array}$ & $\begin{array}{l}.53 \\
.48 \\
.28 \\
.34 \\
.25 \\
.29 \\
.04 \\
.29 \\
.09 \\
.11 \\
.12 \\
.19 \\
.06\end{array}$ & $\begin{array}{l}.17 \\
.20 \\
.15 \\
.19 \\
.14 \\
.20 \\
.03 \\
.29 \\
.10 \\
.15 \\
.15 \\
.15 \\
.10\end{array}$ & $\begin{array}{l}\text { Th } \\
\text { LA } \\
\text { LA } \\
\text { Th } \\
\text { Th } \\
\text { Th } \\
\text { Th } \\
\text { MA } \\
\text { Th } \\
\text { Th } \\
\text { LA } \\
\text { Th } \\
\text { Th }\end{array}$ & $\begin{array}{l}54 \mathrm{~F}(21) \\
65 \mathrm{M}(22) \\
57 \mathrm{M}(8) \\
67 \mathrm{~F}(6) \\
61 \mathrm{~F}(24) \\
67 \mathrm{M}(15) \\
79 \mathrm{M}(19) \\
67 \mathrm{~F}(6) \\
50 \mathrm{M}(4) \\
49 \mathrm{M}(17) \\
59 \mathrm{~F}(3) \\
80 \mathrm{~F}(26) \\
61 \mathrm{~F}(12)\end{array}$ & $\begin{array}{l}\text { WN } \\
\text { WN } \\
\text { WN } \\
\text { WN } \\
\text { E } \\
\text { WN } \\
\text { E } \\
\text { WN } \\
\text { PN } \\
\text { WN } \\
\text { WN } \\
\text { WN } \\
\text { WN }\end{array}$ \\
\hline $\begin{array}{ll}2 & 1 / 2 \\
2 & 1 / 2 \\
2 & 1 / 2 \\
2 & 1 / 2 \\
2 & 1 / 4 \\
2 & 1 / 4 \\
2 & \\
2 \\
2 \\
2 \\
2 \\
2 \\
2 \\
2\end{array}$ & $\begin{array}{r}1.56 \\
1.13 \\
.71 \\
.39 \\
1.17 \\
.62 \\
1.34 \\
1.03 \\
.70 \\
.55 \\
.39 \\
.39 \\
.35\end{array}$ & $\begin{array}{l}.07 \\
.08 \\
.08 \\
.07 \\
.13 \\
.04 \\
.20 \\
.18 \\
.11 \\
.09 \\
.08 \\
.05 \\
.08\end{array}$ & $\begin{array}{l}.04 \\
.07 \\
.12 \\
.18 \\
.11 \\
.06 \\
.15 \\
.18 \\
.16 \\
.16 \\
.21 \\
.14 \\
.24\end{array}$ & $\begin{array}{l}\text { Th } \\
\text { Th } \\
\text { Th } \\
\text { Th } \\
\text { Th } \\
\text { Th } \\
\text { Th } \\
\text { MA } \\
\text { MA } \\
\text { MA } \\
\text { Th } \\
\text { LA } \\
\text { Th }\end{array}$ & $\begin{array}{l}78 \mathrm{M}(1) \\
50 \mathrm{M}(27) \\
63 \mathrm{M}(18) \\
71 \mathrm{M}(23) \\
73 \mathrm{M}(9) \\
64 \mathrm{M}(2) \\
67 \mathrm{M}(5) \\
59 \mathrm{~F}(3) \\
71 \mathrm{M}(23) \\
65 \mathrm{M}(22) \\
54 \mathrm{~F}(16) \\
71 \mathrm{M}(23) \\
52 \mathrm{M}(11)\end{array}$ & $\begin{array}{l}\text { E } \\
\text { WN } \\
\text { WN } \\
\text { PN } \\
\text { PN } \\
\text { PN } \\
\text { WN } \\
\text { WN } \\
\text { PN } \\
\text { WN } \\
\text { WN } \\
\text { PN } \\
\text { E }\end{array}$ \\
\hline $\begin{array}{ll}2 \\
2 \\
1 & 3 / 4 \\
1 & 3 / 4 \\
1 & 1 / 2 \\
1 & 1 / 2 \\
1 & 1 / 2 \\
1 & 1 / 2 \\
1 & 1 / 2 \\
1 & 1 / 2 \\
1 & \\
1 & \\
1 & \\
1 & \end{array}$ & $\begin{array}{l}.32 \\
.28 \\
.79 \\
.45 \\
.66 \\
.35 \\
.22 \\
.18 \\
.12 \\
.11 \\
.31 \\
.23 \\
.18 \\
.18\end{array}$ & $\begin{array}{l}.03 \\
.05 \\
.11 \\
.03 \\
.09 \\
.03 \\
.02 \\
.01 \\
.01 \\
.02 \\
.03 \\
.03 \\
.03 \\
.03\end{array}$ & $\begin{array}{l}.09 \\
.18 \\
.14 \\
.07 \\
.14 \\
.09 \\
.11 \\
.06 \\
.05 \\
.18 \\
.09 \\
.14 \\
.16 \\
.16\end{array}$ & $\begin{array}{l}\text { MA } \\
\text { Th } \\
\text { Th } \\
\text { MA } \\
\text { Th } \\
\text { Th } \\
\text { LA } \\
\text { Th } \\
\text { MA } \\
\text { LA } \\
\text { Th } \\
\text { LA } \\
\text { MA } \\
\text { Th }\end{array}$ & $\begin{array}{l}50 \mathrm{M}(4) \\
65 \mathrm{M}(22) \\
59 \mathrm{~F}(3) \\
64 \mathrm{M}(2) \\
57 \mathrm{M}(8) \\
51 \mathrm{M}(10) \\
50 \mathrm{M}(4) \\
38 \mathrm{~F}(7) \\
38 \mathrm{~F}(7) \\
38 \mathrm{~F}(7) \\
42 \mathrm{M}(25) \\
32 \mathrm{~F}(28) \\
32 \mathrm{~F}(28) \\
32 \mathrm{~F}(28)\end{array}$ & $\begin{array}{l}\text { PN } \\
\text { WN } \\
\text { WN } \\
\text { PN } \\
\text { WN } \\
\text { WN } \\
\text { PN } \\
\text { E } \\
\text { E } \\
\text { E } \\
\text { WN } \\
\text { WN } \\
\text { WN } \\
\text { WN }\end{array}$ \\
\hline
\end{tabular}

* Severity of atherosclerosis is estimated by averaging two grades, one of which indicates the extent of atherosclerotic lesions, the other their character.

$\uparrow$ Ratio is the ratio of carotenoids in micrograms to cholesterol in milligrams.

† Aortic zone: Th, Thoracic Aorta; MA, Midabdominal Aorta; LA, Lower Abdominal Aorta.

The number in parentheses is a code number assigned to each patient; 12 patients had more than one area of the aorta examined.

Utate of nutrition: WN, Well Nourished; PN, Poorly Nourished; E, Emaciated.

This aorta had extensive medical calcification with involvement of the adventitia in addition to atherosclerosis. 
TABLE II

Quarterly average values, data from Table I

\begin{tabular}{|c|c|c|c|c|}
\hline Quarter & $\begin{array}{c}\text { Severity } \\
\text { of athero- } \\
\text { sclerosis }\end{array}$ & 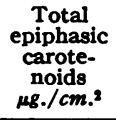 & $\begin{array}{c}\text { Total } \\
\text { choles- } \\
\text { terol } \\
\text { mg./cm.2 }\end{array}$ & $\frac{\text { Carotenoids } \mu \mathrm{g}}{\text { Cholesterol } \mathrm{mg}}$ \\
\hline $\begin{array}{l}1 \\
2 \\
3 \\
4\end{array}$ & 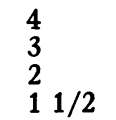 & $\begin{array}{l}.65 \\
.24 \\
.10 \\
.04\end{array}$ & $\begin{array}{l}3.9 \\
1.4 \\
.71 \\
.31\end{array}$ & $\begin{array}{l}.17 \\
.16 \\
.14 \\
.13\end{array}$ \\
\hline
\end{tabular}

tissue concentrations to negligible amounts (15). In addition, the signs of Vitamin A deficiency produced can be promptly relieved by administration of carotenoids (15). The present findings therefore give evidence that one dietary lipid not only is present in atherosclerotic plaques but accumulates in direct proportion to age and extent of the lesions.

It is unknown whether carotenoid pigments are concerned with the production of atherosclerotic plaques or if their role is of a secondary nature. It has been suggested by earlier investigators that the presence of carotenoids in atherosclerosis stems from the solubility of these pigments in the other lipids present (2). Although this may be the case, there is evidence that other factors are of more importance in determining their distribution. Some areas high in lipid contain only negligible concentrations of carotenoids (16). The electrophoresis of serum yields a distribution of carotenoids different from total lipid or any demonstrable individual lipid (17). If the solubility of carotenoids in other lipids were to determine their distribution, they would be carried with the lipids in which they are dissolved and show the same mobility. However, this is not the case, and their migration is more suggestive of an affinity for certain proteins (18).

Further studies are indicated on the mechanism of carotenoid accumulation in atherosclerotic plaques. The use of these pigments may prove to be a useful aid in the study of atherosclerosis.

\section{SUMMARY}

Studies have been made on the concentrations of carotenoids and cholesterol in human atherosclerotic lesions. The findings indicate that these substances increase in concentration with extent and relative age of lesions. The carotenoid-cholesterol ratio is not significantly changed. Hence, one lipid of exogenous origin is shown to accumu- late in plaques in direct proportion to the severity of atherosclerosis.

\section{REFERENCES}

1. Karrer, P., and Jucker, E., Carotenoids. New York, Elsevier Publishing Co., 1950.

2. Thomson, J. G., Uber Lipochrome im Menschlichen Körper. Ztschr.f. d. ges. exper. med., 1934, 92, 692.

3. Hirsch, E. F., The chemistry of atherosclerosis in man and its pathogenesis as indicated by animal experiments. Tr. Am. Therap. Soc., 1948, 49, 113.

4. McArthur, C. S., The acetone-soluble lipid of the atheromatous aorta. Biochem. J., 1942, 36, 559.

5. Meeker, D. R., and Jobling, J. W., A chemical study of atherosclerotic lesions in the human aorta. Arch. Path., 1934, 18, 252.

6. Zeek, P. M., A chemical analysis of atherosclerotic lesions in human aortas. Am. J. Path., 1936, 12, 115.

7. McMillan, G. C., Horlick, L., and Duff, G. L., Cholesterol content of aorta in relation to severity of atherosclerosis. Studies during progression and retrogression of experimental lesions. Arch. Path., 1955, 59, 285.

8. Kimble, M. S., The photocolorimetric determination of vitamin $\mathrm{A}$ and carotene in human plasma. J. Lab. \& Clin. Med., 1939, 24, 1055.

9. Bessey, O. A., Lowry, O. H., Brock, M. J., and Lopez, J. A., The determination of vitamin A and carotene in small quantities of blood serum. J. Biol. Chem., 1946, 166, 177.

10. Abell, L. L., Levy, B. B., Brodie, B. B., and Kendall, F. E., A simplified method for the estimation of total cholesterol in serum and demonstration of its specificity. J. Biol. Chem., 1952, 195, 357.

11. Sperry, W. M., and Webb, M., A revision of the Schoenheimer-Sperry method for cholesterol determination. J. Biol. Chem., 1950, 187, 97.

12. Smakula, A., Lichtabsorption und Chemische Konstitution. Angewandte Chemie, 1934, 47, 657.

13. May, C. D., Blackfan, K. D., McCreary, J. F., and Allen, F. H., Jr., Clinical studies of vitamin A in infants and in children. Am. J. Dis. Child., 1940, 59, 1167.

14. Ayers, G. H., Evaluation of accuracy in photometric analysis. Anal. Chem., 1949, $21,652$.

15. Hume, E. M., and Krebs, H. A., Vitamin A requirement of human adults. An experimental study of Vitamin A deprivation in man. Medical Research Council Special Report, series no. 264, 1949.

16. Clausen, S. W., The absorption of Vitamin A and its storage in the tissues. Harvey Lect., Series 38, 1942-1943, Lancaster, Pa., The Science Press Printing Co., 1943.

17. Kunkel, H. G., and Slater, R. J., Lipoprotein patterns of serum obtained by zone electrophoresis. J. Clin. Invest., 1952, 31, 677.

18. Crook, E. M., and El-Marsafy, M. K., Association of carotene with serum proteins. Biochem. J., 1954, 57, viii. 